\title{
Landslide susceptibility evaluation based on GIS and information value model
}

\author{
Chen Yumin ${ }^{1, ~ a ~}$, Ba Qianqian ${ }^{1, b}$, Wu Qianjiao ${ }^{1, c}$ and Li Xiangfei ${ }^{1, d}$ \\ ${ }^{1}$ School of Resource and Environment Science, Wuhan University, 129 Luoyu Road, Wuhan, \\ 430079, China \\ aymchen@whu.edu.cn, bbaqianq@whu.edu.cn, ${ }^{\mathrm{c}}$ carol@whu.edu.cn, ${ }^{\mathrm{d}} \mathrm{xiangfeili@whu.edu.cn}$
}

Keywords: Landslide; Information value model; Susceptibility evaluation

\begin{abstract}
The western region of Chongqing seriously suffers from landslides. This paper evaluate the landslide hazard using GIS (Geographic Information System) technology and information value model and selecting seven influential factors including slope, aspect, elevation, rain, river, road and geological structure. The results show that the southern region of the study area are the most hazardous region. From the evaluation results, $20.6 \%$ of the total area suffers from high landslide risk and $13.1 \%$ suffers from very high risk, which is of important practical and immediate significance to the landslide prevention and reduction in the area. The evaluation result is basically coincident with the reality. The study further demonstrates that the information value model combined with geographical information system can quickly and effectively evaluate the spatial distribution and risk of the landslide hazard.
\end{abstract}

\section{Introduction}

China is one of the geological disaster-prone countries. Landslides are one of the most important natural hazards. Every year, the economic losses and causalities as a result of landslides are greater than what is common knowledge. To minimize economic losses and the loss of human life, landslide-prone areas should be identified.

With the rapid development of GIS, the geological hazard researches were dramatically improved and enhanced. Combined with the evaluation models, GIS technology is an effective tool of landslide risk evaluation, and the evaluation results can be used to prevent and mitigate the hazard.

At present, landslide susceptibility evaluation models commonly include: fuzzy evaluation method, artificial neural network model, logistic regression model, information value model, analytic hierarchy process, etc. E. Yesilnacar and T. Topal ${ }^{[1]}$ evaluated the landslide hazard in the Hendek region of Turkey under the medium scale conditions, and compared and analyzed the results of the logistic regression model and neural network model. A Nandi et al. ${ }^{[2]}$ evaluated the landslide susceptibility of Cuyahoga River Basin in northeast Ohio, based on GIS technology and multivariate statistical model; Huo Ai-di ${ }^{[3]}$ research the method of classification for susceptibility assessment unit for geological hazard,and used slope units to evaluate geo-hazard susceptibility based on GIS technology in Huangling County of Yan' an City;Wei Chen and Wenping $\mathrm{Li}^{[4]}$ drawed the landslide susceptibility zoning map based on GIS and information value model for the Chencang District of Baoji;L. P. Sharma ${ }^{[5]}$ researched the application of Shannon's entropy integrated information value model for landslide susceptibility assessment and zonation in Sikkim Himalayas in India.

In conclusion, in the process of the geological hazard susceptibility assessment, previous researches have used a combination of GIS and the statistical method. However, the weights and classification of the influential factors basically depends on the experience,which is lacking in the theoretical fundament,therefore the accuracy of the model calculation will be seriously affected.Information value model is a kind of statistical analysis model.Because of its clear physical meaning and simple operation, information value model has been widely used in the landslide susceptibility evaluation. This paper use the information value model to evaluate the landslide hazard prone of the western region of Chongqing, and compare the evaluation results with the actual 
situation. Use these results to help the relevant departments to carry out disaster prevention and mitigation work.

\section{Methodology}

The method used for this study is the evaluation unit classification and information value model.

The theoretical principle of information value model is information theory. Information theory was founded by C.E.S hannon. Mr. Tonzhen Yan firstly applied the theory to landslide forecast, and then it was widely used to the evaluation of geological hazard by many scholars. The possibility of landslide hazard is characterized by the entropy.

As is known to us, whether wills a landslide happen is affected by many factors and different factors play different roles. In different factors, "best combinations" can always be founded; Its landslide "contribution" is the largest. Therefore, the research of landslides is to find the "best combinations" . The greater the amount of information, the greater the likelihood of a landslide. The formula is as follows:

$$
\mathrm{I}\left(\mathrm{y}, x_{1} x_{2} \cdots x_{n}\right)=\log _{2} \frac{P\left(y \mid x_{1} x_{2} \cdots x_{n}\right)}{P(y)}
$$

In this expression, $\mathrm{I}\left(\mathrm{y}, x_{1} x_{2} \cdots x_{n}\right)$ is the information of specific factor combination $x_{1} x_{2} \cdots x_{n}$ for the landslide. $P\left(y \mid x_{1} x_{2} \cdots x_{n}\right)$ is the probability of landslide occurrence under combinations of factors. $P(y)$ is the probability of landslide occurrence.

The landslide susceptibility evaluation is based on the division of the evaluation cells in the study area. Assume that the region is divided into $\mathrm{N}$ units, and there are $\mathrm{N}_{0}$ units of landslide hazard, $\mathrm{M}$ units with the same factor combination $x_{1} x_{2} \cdots x_{n}, \mathrm{M}_{0}$ units of landslide hazard with the same combination factor $x_{1} x_{2} \cdots x_{n}$.According to the expression (1),the information of the factor $x_{1} x_{2} \cdots x_{n}$ for landslide hazard in the region is:

$$
\mathrm{I}\left(\mathrm{y}, x_{1} x_{2} \cdots x_{n}\right)=\log _{2} \frac{M_{0} / M}{N_{0} / N}
$$

In general, due to the limited number of sample statistics,we use the stepwise calculation of simplified single factor information value model and overlay analysis. The corresponding information model is rewritten as:

$$
\mathrm{I}=\sum_{i=1}^{n} I_{i}=\sum_{i=1}^{n} \log _{2} \frac{S_{0}{ }^{i} / S^{i}}{A_{0} / A}
$$

I means the information value of the unit in the region. $S^{i}$ refers to the total area of the factor $x_{\mathrm{i}}$ units. $S_{0}{ }^{i}$ is the total area of the factor $x_{\mathrm{i}}$ units with landslide hazard. $A$ is the total area of the region. $A_{0}$ means the total area of units with landslide hazard.

\section{Experiments}

Landslide susceptibility evaluation is a comprehensive work based on the enormous data and the influential factors. Our approach is as follows: (1) to prepare the landslide data and environmental factors including elevation, slope, aspect, river, road, structure and rain;(2) to select the evaluation unit;(3) to classify each environmental factor and calculate its information value of each classification of the influential factors using information value model;(4) to determine the comprehensive information value using the GIS spatial analysis;(5) to divide study area into five levels. The levels are very low, low, moderate, high and very high.

\subsection{Study area \& data sources}

This paper select the western region of Chongqing as the study area. The study area is located in the eastern part of Sichuan Basin and bounded roughly by longitudes of $105^{\circ} 16^{\prime} \mathrm{E}$ and $106^{\circ} 57^{\prime} \mathrm{E}$ and latitudes of $28^{\circ} 35^{\prime} \mathrm{N}$ and $30^{\circ} 26^{\prime} \mathrm{N}$, with complex geological structure, soft surface layer, deep valleys and steep slopes. The mainstreams and tributaries of Jialing River, the Yangtze River run 
through the whole region. In addition, this area is subjected to the influence of subtropical monsoon climate, with abundant precipitation and stormrain. In recent years, due to the establishment of the municipality and the construction of the Three Gorges project, the impact of human economic activities have become increasingly intensified.Therefore, landslide is the most serious geological hazard in the area.

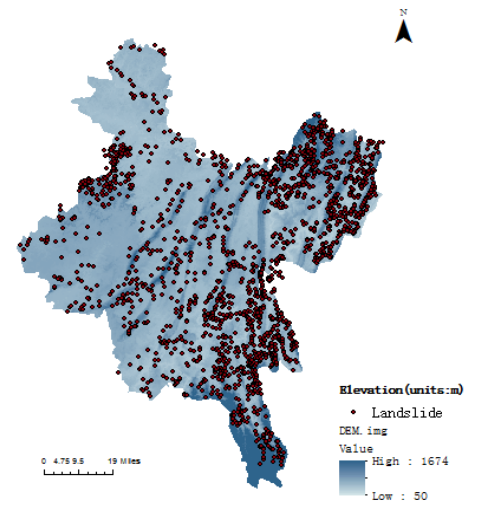

Fig. 1 Topographic map of study area showing the location. Points indicate past of landslide events In this study, the elevation, slope and aspect are derived from the advanced spaceborne thermal emission and reflection radiometer global digital elevation model (ASTER GRTM). The spatial resolution of the DEM is $30 \times 30 \mathrm{~m}$. The geological structure data are obtained from the geological map of Chongqing. The scale is 1:500000. The river and road data are from the basic geographic information database. The scale is 1:4000000.The rain and landslide data are from Chongqing Institute of Geology and mineral resources.

\subsection{The calculation of information value for influential factor}

This paper selects the elevation, slope, aspect, the distance from river, road and structure and rain as influential factors. Then grade every influential factor by the reclassify of GIS. Using GIS spatial analysis, the study calculate the information value of influential factors.

\subsection{Landslide susceptibility evaluation}

We determine the susceptibility by comprehensive information which is calculated by adding the seven information values computed from seven influential factors together. Comprehensive information is divided into five ranks according to the natural breakpoint.

\section{Results}

Table 1 show the information value of seven influential factors. Information value layer of seven influential factors are shown in the Fig. 2. Table 2 show the classifications of comprehensive information. The final landslide susceptibility mapping is shown in Fig. 3.

Table1 Information value of seven influential factors

\begin{tabular}{|c|c|c|c|c|c|c|c|c|c|}
\hline Factor & Class & $\mathbf{A}_{0}$ & $S_{0}$ & I & Factor & Class & $\mathbf{A}_{0}$ & $S_{0}$ & I \\
\hline \multirow{5}{*}{$\begin{array}{c}\text { Elevatio } \\
-\mathbf{n}\end{array}$} & 204.09 & -0.2801 & 74.69 & 0.3766 & \multirow{9}{*}{ Aspect } & Flat & 12579 & 12.26 & -0.3353 \\
\hline & $300-600$ & 1315682 & 1325.07 & -0.3034 & & $\mathrm{~N}$ & 189184 & 237.11 & -0.0839 \\
\hline & $600-900$ & 317238 & 613.46 & 0.3489 & & EN & 198140 & 204.09 & -0.2801 \\
\hline & $900-1200$ & 69812 & 293.69 & 1.1262 & & $\mathrm{E}$ & 251997 & 353.59 & 0.0290 \\
\hline & $>1200$ & 66812 & 158.29 & 0.5520 & & ES & 261233 & 302.96 & -0.1615 \\
\hline \multirow{7}{*}{ Slope } & $0-10$ & 1356684 & 1268.62 & -0.3777 & & $\mathrm{~S}$ & 206820 & 353.59 & 0.0290 \\
\hline & $10-20$ & 334603 & 876.37 & 0.6523 & & WS & 197576 & 258.75 & -0.04 \\
\hline & $20-30$ & 92876 & 201.56 & 0.4643 & & W & 249859 & 513.70 & 0.4110 \\
\hline & $30-40$ & 18614 & 75.86 & 1.0944 & & WN & 239728 & 323.81 & -0.0091 \\
\hline & $40-50$ & 4024 & 0.8 & -1.926 & \multirow[b]{3}{*}{ River } & $0-800$ & 187241 & 286.23 & 0.1142 \\
\hline & $>50$ & 315 & 42 & 4.5823 & & $\begin{array}{c}800-1 \\
600\end{array}$ & 156573 & 297.40 & 0.3314 \\
\hline & $0-5$ & 1365769 & 2360.24 & 0.2368 & & $1600-$ & 144768 & 251.82 & 0.2434 \\
\hline
\end{tabular}




\begin{tabular}{|c|c|c|c|c|c|c|c|c|c|}
\hline \multirow{5}{*}{ Rain } & & & & & & 2400 & & & \\
\hline & $5-10$ & 167460 & 57.77 & -1.3746 & & $\begin{array}{c}2400- \\
3200\end{array}$ & 136597 & 179.73 & -0.0358 \\
\hline & $10-20$ & 162028 & 32.47 & -1.9176 & & $\begin{array}{c}3200- \\
4000\end{array}$ & 127803 & 137.34 & -0.2382 \\
\hline & $20-30$ & 40260 & 7.93 & -1.935 & & $\begin{array}{c}4000- \\
4800\end{array}$ & 117082 & 124.89 & -0.2456 \\
\hline & $>30$ & 72205 & 6.81 & -2.6717 & & $>4800$ & 937654 & $\begin{array}{c}1187.7 \\
9\end{array}$ & -0.0737 \\
\hline \multirow{7}{*}{ Road } & $0-800$ & 103387 & 225.01 & 0.4674 & \multirow{7}{*}{$\begin{array}{c}\text { Structu } \\
\text {-re }\end{array}$} & $0-600$ & 103387 & $\begin{array}{c}403.98 \\
1\end{array}$ & 0.2597 \\
\hline & $800-1600$ & 97556 & 124.75 & -0.0644 & & $\begin{array}{c}600-1 \\
200\end{array}$ & 231898 & 386.94 & 0.2018 \\
\hline & $1600-2400$ & 90191 & 145.64 & 0.1690 & & $\begin{array}{l}1200- \\
1800\end{array}$ & 230664 & 336.97 & 0.0688 \\
\hline & $2400-3200$ & 82032 & 98.58 & -0.1265 & & $\begin{array}{l}1800- \\
2400\end{array}$ & 217780 & 343.63 & 0.1459 \\
\hline & $3200-4000$ & 76853 & 66.93 & -0.4485 & & $\begin{array}{c}2400- \\
3000\end{array}$ & 192603 & 165.21 & -0.4636 \\
\hline & $4000-4800$ & 73302 & 112.75 & 0.1204 & & $\begin{array}{c}3000- \\
3600 \\
\end{array}$ & 148947 & 89.33 & -0.8215 \\
\hline & $>4800$ & 1284397 & 1691.56 & -0.0349 & & $>3600$ & 557343 & 739.16 & -0.0279 \\
\hline
\end{tabular}

(a)

(b)

(c)

(d)

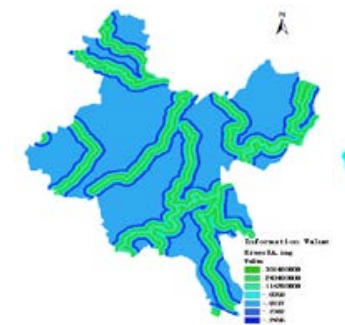

(e)

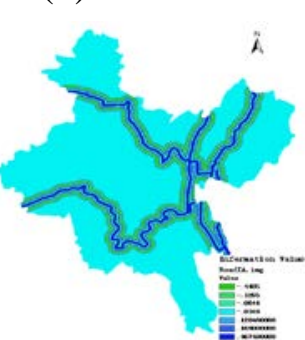

(f)

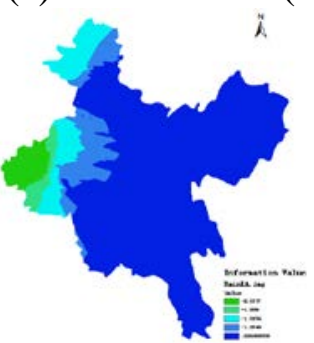

(g)

Fig. 2 Information value layer of seven influential factors. a slope, b aspect, c elevation, d geological structure, e road, f river, g rain

Table 2 Classifications of comprehensive information

\begin{tabular}{llclcc} 
Classifications & Very low & Low & Moderate & High & Very High \\
Comprehensive & $-4.6182-$ & $-2.0889-$ & $-0.9399-$ & $-0.0451-$ & $0.9282-$ \\
information & -2.0889 & -0.9399 & -0.0451 & 0.9282 & 6.9125 \\
\hline
\end{tabular}




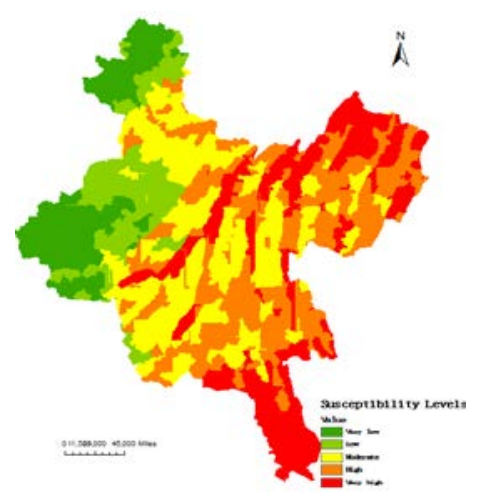

Fig. 3 Landslide risk zonation map

The results of comparing with susceptible classification and the distribution of landslide are shown in Table 3.A is the number of grids in every evaluation classification. $\mathrm{R}_{\mathrm{a}}$ is the evaluation classification percentage of the total grid number. $\mathrm{L}$ refers to the area of landslide. $\mathrm{R}$ is the percentage of the total landslide area. $\mathrm{B}$ refers to the proportion covered by the population of the landslide area in the evaluation classification area.I is the information value.

Table 3 Comparison of evaluation results and actual occurrence

\begin{tabular}{lllllll} 
Classifications & $\mathbf{A}$ & $\mathbf{R}_{\mathbf{a}}$ & $\mathbf{L}$ & $\mathbf{R}$ & $\mathbf{B}$ & $\mathbf{I}$ \\
\hline Very low & 318696 & 0.1766 & 46.0045 & 0.0187 & 0.0178 & -2.2452 \\
\hline Low & 256925 & 0.1424 & 128.73 & 0.0523 & 0.0619 & -1.0007 \\
\hline Moderate & 621530 & 0.3444 & 618.5517 & 0.2515 & 0.1229 & -0.3145 \\
\hline High & 371481 & 0.2058 & 828.2064 & 0.3367 & 0.2752 & 0.4921 \\
\hline Very high & 236088 & 0.1308 & 838.2759 & 0.3408 & 0.4384 & 0.9575 \\
\hline
\end{tabular}

\section{Conclusion}

Landslides are one of the most hazardous nature disasters. This paper use information value model which is a kind of statistic model and GIS to evaluate the landslide hazard in the western region of Chongqing.The conclusions can be summarized as follows:

(1) This paper use GIS and information value model to evaluate the landslide hazard in the study area.High hazard and very high hazard areas are located in the southern region.

(2) This paper selects six indexes to validate the evaluation results. These results indicate that information value model has a high accuracy of landslide susceptibility evaluation.

This paper uses information value model to evaluate landslide susceptibility in the western region of Chongqing. However,information value model neglects the weights of different factors, which will seriously affect the reasonableness of the evaluation results.Our future work will be on the improvement of information value model and the scale effect of landslide susceptibility evaluation.

\section{Acknowledgements}

The research was supported by grants from National High Technology Research and Development Program of China (Project No. 2013AA122302,2013AA122301), National Nature Science Foundation of China (Project No.41171347).

\section{References}

[1] Yesilnacar, E., and T. Topal. "Landslide susceptibility mapping: a comparison of logistic regression and neural networks methods in a medium scale study, Hendek region (Turkey)." Engineering Geology 79.3 (2005): 251-266.

[2] Nandi, A, and A. Shakoor. "A GIS-based landslide susceptibility evaluation using bivariate and multivariate statistical analyses." Engineering Geology110.1 (2010): 11-20. 
[3] Ai-di, Huo, et al. "A sampled method of classification of susceptibility evaluation unit for geological hazards based on GIS." Applied Mathematics \& Information Sciences 6 (2012): 19-23.

[4] Chen, Wei, et al. "Landslide susceptibility mapping based on GIS and information value model for the Chencang District of Baoji, China." Arabian Journal of Geosciences 7.11 (2014): 4499-4511.

[5] Sharma, L. P., et al. "Development and application of Shannon's entropy integrated information value model for landslide susceptibility assessment and zonation in Sikkim Himalayas in India." Natural Hazards 75.2 (2015): 1555-1576. 